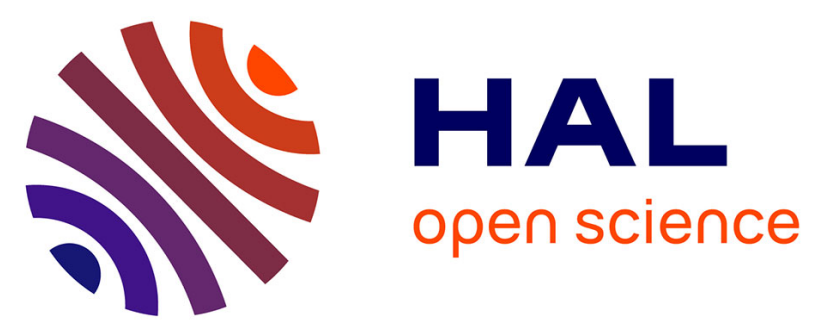

\title{
Study of annealing-induced interdiffusion in In_2O_3/Ag/In_2O_3 structures by a combined X-ray reflectivity and grazing incidence $\mathrm{X}$-ray fluorescence analysis
}

Béranger Caby, Fabio Brigidi, D. Ingerle, Emmanuel Nolot, Giancarlo

Pepponi, Christina Streli, Luca Lutterotti, Agathe André, Guillaume

Rodriguez, Patrice Gergaud, et al.

\section{- To cite this version:}

Béranger Caby, Fabio Brigidi, D. Ingerle, Emmanuel Nolot, Giancarlo Pepponi, et al.. Study of annealing-induced interdiffusion in In_2O_3/Ag/In_2O_3 structures by a combined X-ray reflectivity and grazing incidence X-ray fluorescence analysis. Spectrochimica Acta Part B: Atomic Spectroscopy, 2015, 113, pp.132-137. 10.1016/j.sab.2015.09.008 . cea-02957349

HAL Id: cea-02957349

https://hal-cea.archives-ouvertes.fr/cea-02957349

Submitted on 5 Oct 2020

HAL is a multi-disciplinary open access archive for the deposit and dissemination of scientific research documents, whether they are published or not. The documents may come from teaching and research institutions in France or abroad, or from public or private research centers.
L'archive ouverte pluridisciplinaire HAL, est destinée au dépôt et à la diffusion de documents scientifiques de niveau recherche, publiés ou non, émanant des établissements d'enseignement et de recherche français ou étrangers, des laboratoires publics ou privés.

\section{(ㄷ)(i)}

Distributed under a Creative Commons Attribution| 4.0 International License 


\title{
Study of annealing-induced interdiffusion in $\operatorname{In}_{2} \mathrm{O}_{3} / \mathrm{Ag} / \mathrm{In}_{2} \mathrm{O}_{3}$ structures by a combined $\mathrm{X}$-ray reflectivity and grazing incidence $\mathrm{X}$-ray fluorescence analysis
}

\author{
Bérenger Caby ${ }^{\mathrm{a}, *}$, Fabio Brigidi ${ }^{\mathrm{d}, \mathrm{g}}$, Dieter Ingerle ${ }^{\mathrm{f}}$, Emmanuel Nolot ${ }^{\mathrm{a}}$, Giancarlo Pepponi ${ }^{\mathrm{d}}$, Christina Streli ${ }^{\mathrm{f}}$, \\ Luca Lutterotti ${ }^{\text {, }}$ Agathe André ${ }^{\text {a }}$, Guillaume Rodriguez ${ }^{\mathrm{a}}$, Patrice Gergaud ${ }^{\mathrm{a}}$, \\ Magali Morales ${ }^{\mathrm{c}}$, Daniel Chateigner ${ }^{\mathrm{b}}$ \\ a CEA, LETI, MINATEC Campus, 17 rue des Martyrs, 38054 Grenoble Cedex 9, France \\ b CRISMAT-ENSICAEN, IUT-Caen UCBN, 6 boulevard du Maréchal Juin, 14050 Caen Cedex 4, France \\ c CIMAP, 6 boulevard du Maréchal Juin, 14050 Caen Cedex 4, France \\ ${ }^{\mathrm{d}}$ MNF, CMM-Irst, Fondazione Bruno Kessler Via Sommarive 18, Povo, Trento 38123, Italy \\ e Department of Industrial Physics, University of Trento, via Sommarive 14, Povo, Trento 38123, Italy \\ ${ }^{\mathrm{f}}$ Atominstitut, Vienna University of Technology, Vienne 1020, Austria \\ ${ }^{g}$ Department of Industrial Engineering, University of Trento, via Sommarive 9, Povo, Trento 38123, Italy
}

\section{A R T I C L E I N F O}

\section{Article history:}

Received 7 May 2015

Accepted 7 September 2015

Available online 16 September 2015

\section{Keywords:}

XRR

GIXRF

Depth-profiling

Thin layer characterization

\begin{abstract}
A B S T R A C T
The combination of X-ray reflectivity and grazing incidence X-ray fluorescence has been applied to the characterization of an $\mathrm{In}_{2} \mathrm{O}_{3} / \mathrm{Ag} / \mathrm{In}_{2} \mathrm{O}_{3}$ stack for advanced photovoltaic applications. X-ray reflectivity is a well-known method for the characterization of multilayered structures by providing information on the thickness and the in-depth electronic density. Grazing incidence X-ray fluorescence provides information about the elemental depth distribution. As these techniques are based on similar measurement procedures and data evaluation approaches, their combination reduces the uncertainties of the individual techniques and provides an accurate depth-resolving analysis of multi-layers.

It has been shown that the combination of the techniques give insight into the material composition and the layers structure (thickness, density) as well as modifications induced by a thermal annealing.

As X-ray fluorescence signals have been acquired at different excitation energies, the influence of this parameter on the sensitivity of the measurements to the structural properties has been shown.
\end{abstract}

(c) 2015 Elsevier B.V. All rights reserved.

\section{Introduction}

Transparent and conductive oxide (TCO) layers are essential components in several emerging photosensitive electronic products. Metaloxides such as $\mathrm{SnO}_{2}, \mathrm{In}_{2} \mathrm{O}_{3}$, or $\mathrm{ZnO}$ have widely been used acting as transparent electrical contacts or electrodes in flat panel displays, touch screens, and thin film solar cells [1,2].

There is a wide range of requirements for these layers depending on the application. First, resistivity needs to be tailored to meet the electrical functionality. For solar cells, the sheet resistance $\left(R_{S}\right)$ must be in the $8-80 \Omega$ /sq range [3]. The other key factor is the optical transmission $(T)$ of the layers. For photovoltaic applications, the material must be transparent in the visible spectral range.

Due to a technological need for large-area photovoltaic devices with improved electrical and optical performances, the development of new structures is necessary. Recent investigations have shown that TCO/

\footnotetext{
* Corresponding author. Tel.: + 33438781906.

E-mail address: berenger.caby@cea.fr (B. Caby).
}

metal/TCO multilayer systems are suitable as transparent conductive electrodes for photovoltaic devices [4,5].

To achieve the best balance between the optical and electrical properties of the structure, the metal layer has to be a low-resistivity material and $\mathrm{Ag}\left(1.6 \mu \Omega \mathrm{cm}\right.$ at $\left.20^{\circ} \mathrm{C}\right)$ is the most common interlayer used for TCO/metal/TCO electrodes [6]. Due to its high transmittance in the visible spectral range, indium oxide $\left(\mathrm{In}_{2} \mathrm{O}_{3}\right)$ also referenced as $\mathrm{IO}$ is used to embed the conductive layer. Moreover, the thickness of the layers has an important effect on the electrical conductivity and optical transmittance. As shown on Fig. 1 and by extrapolating from Fig. 2, a $6 \mathrm{~nm}$ thick $\mathrm{Ag}$ film embedded between two $40 \mathrm{~nm}$ thick IO films gives the best compromise between resistivity and transparency and hence the best performances for photovoltaic applications.

A combination of X-ray reflectivity (XRR) and grazing incidence $\mathrm{X}$-ray fluorescence (GIXRF) measurements have been performed on such $\mathrm{IO} / \mathrm{Ag} / \mathrm{IO}$ structures. This approach has been carried out with the idea that the combined analysis would provide more detailed information than the sum of the individual techniques about the layer structure and its possible modifications due to a thermal annealing. 


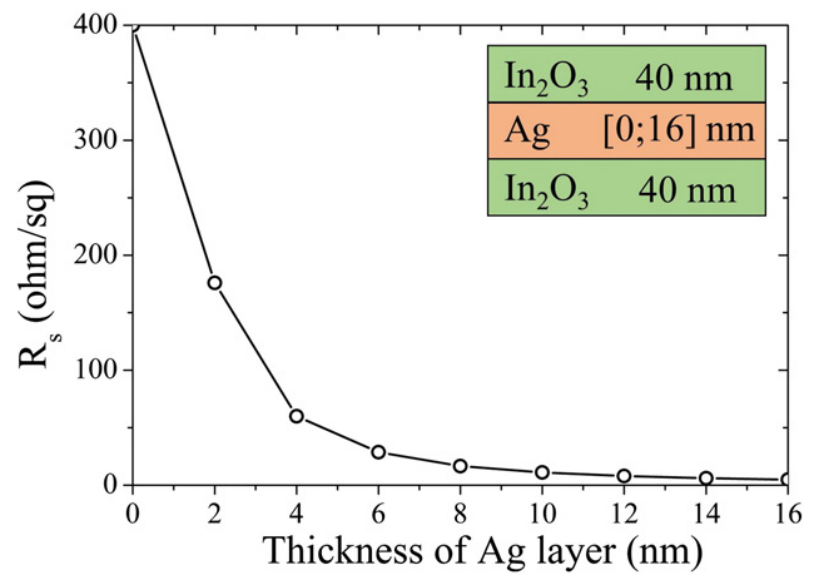

Fig. 1. Sheet resistance for $\mathrm{IO} / \mathrm{Ag} / \mathrm{IO}$ tri-layer samples with an $\mathrm{Ag}$ layer with varying thickness. $0 \mathrm{~nm}$ of $\mathrm{Ag}$ represents the sheet resistance of an $80 \mathrm{~nm}$ pure $\mathrm{In}_{2} \mathrm{O}_{3}$ layer. For photovoltaic applications, acceptable sheet resistances have been obtained with $\mathrm{Ag}$ thickness superior to $4 \mathrm{~nm}$.

GIXRF experiments have already been mainly employed for the characterization of thin films $[7,8]$. At incidence angles close to the critical angle of total external reflection, due to the interference between the incoming and the reflected beam, an X-ray standing wave field (XSW) is created above and inside the material [9]. By varying the incidence angle, the wave field intensity distribution changes and affects the X-ray fluorescence signal. This angular dependency of the GIXRF signals provides information on the elemental depth distribution as well as the thickness, density, and roughness of thin layers and interfaces.

XRR is a non-destructive, highly accurate method based on the reflection in the specular direction of X-rays at the surface and interfaces of the sample [10] and is used to determine thickness, in-depth electronic density, and roughness of thin layers. Both XRR and GIXRF methods can be operated simultaneously on a unique experimental setup using the same primary X-ray radiation (Fig. 3). The combination of the complementary information that these two techniques provide is used to reduce the uncertainties of the individual methods and allows a determination of the depth profile with a better accuracy [11]. The combined analysis of $\mathrm{IO} / \mathrm{Ag} / \mathrm{IO}$ stacking has been performed in order to obtain the material composition and the layers structure as well as their modifications induced by a thermal annealing.

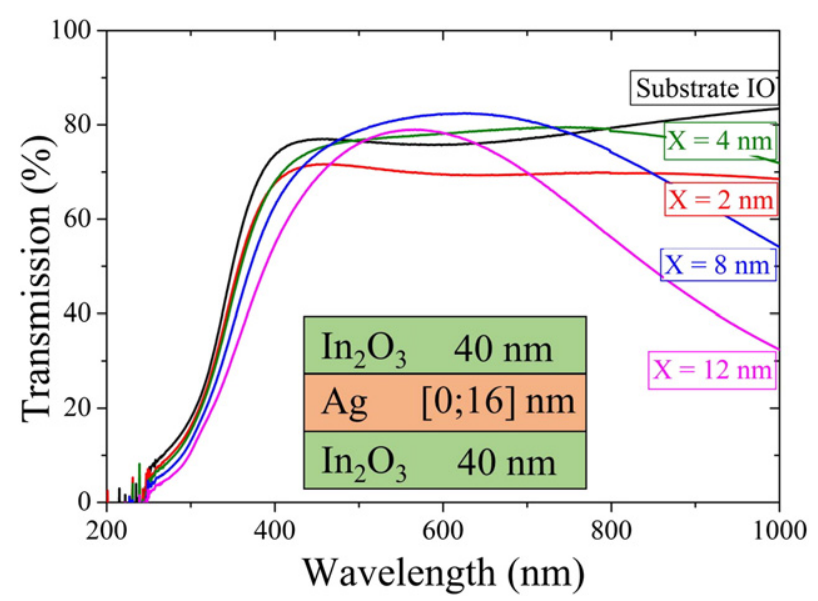

Fig. 2. Optical transmittance for $\mathrm{IO} / \mathrm{Ag} / \mathrm{IO}$ tri-layer samples with an Ag layer with varying thickness. For photovoltaic applications, the transparency in the visible is necessary and sample with an $\mathrm{Ag}$ thickness of $12 \mathrm{~nm}$ are not adapted.

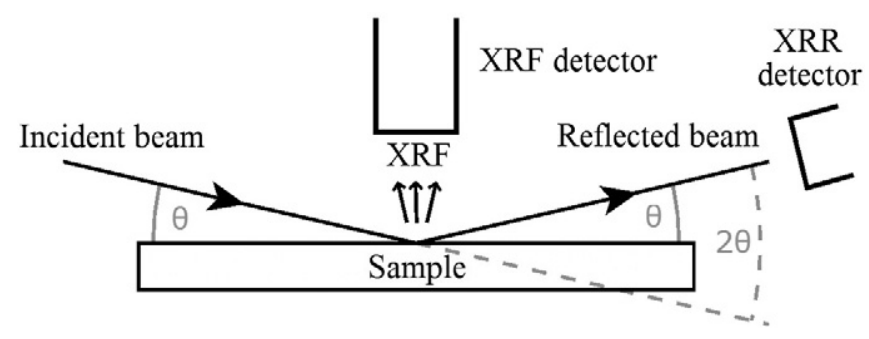

Fig. 3. Experimental setup for combined XRR and GIXRF analysis.

Table 1

Samples analyzed using combined XRR-GIXRF.

\begin{tabular}{lll}
\hline Sample & Top layer & Annealing \\
\hline A & $40 \mathrm{~nm}$ & \\
B & $40 \mathrm{~nm}$ & $200^{\circ} \mathrm{C}$ for $1 \mathrm{~h}$ \\
C & $15 \mathrm{~nm}$ & \\
D & $15 \mathrm{~nm}$ & $200^{\circ} \mathrm{C}$ for $1 \mathrm{~h}$ \\
\hline
\end{tabular}

\section{Experiments}

\subsection{Sample preparation}

The structure of the samples studied by combined XRR-GIXRF analysis consists in a $6 \mathrm{~nm} \mathrm{Ag}$ layer embedded between two $40 \mathrm{~nm} \operatorname{In}_{2} \mathrm{O}_{3}$ layers deposited on a $500 \mathrm{~mm} \mathrm{SiO}_{2} / \mathrm{Si}(001)$ substrate. Each layer has been deposited via PVD (physical vapor deposition) with a low-temperature deposition process.

In order to simulate a realistic technological integration, a thermal budget has been applied to duplicate samples. The annealing has been made in a Tempress furnace system at $200{ }^{\circ} \mathrm{C}$ during $1 \mathrm{~h}$. To improve the sensitivity on the $\mathrm{In}_{2} \mathrm{O}_{3} / \mathrm{Ag}$ interface, the thickness of the top IO layer has been reduced via CMP (chemical mechanical polishing) to a thickness of approximately $15 \mathrm{~nm}$. The same approach was used by Giubertoni et al. to gain sensitivity on buried layers when doing grazing incidence absorption studies [12]. The list of analyzed samples is reported in Table 1.

\subsection{Acquisition}

The first measurement campaign was performed at the Atominstitut (Vienna, Austria) where both XRR and GIXRF measurements have

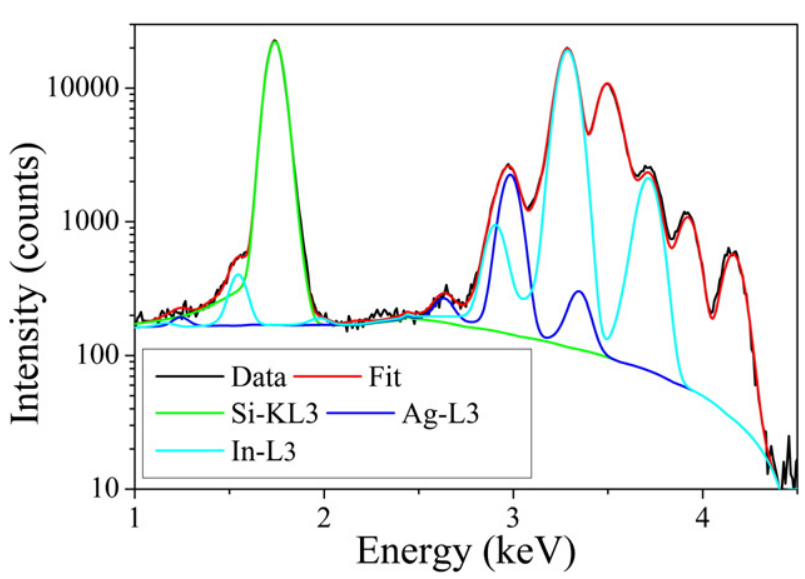

Fig. 4. Fluorescence intensity extraction from a measurement at $1.2^{\circ}$ with a Cu-tube. Due to the correlation of Ag-L3 and In-L3 fluorescence peaks, the use of a third-party software like PyMCA [14] is necessary. 


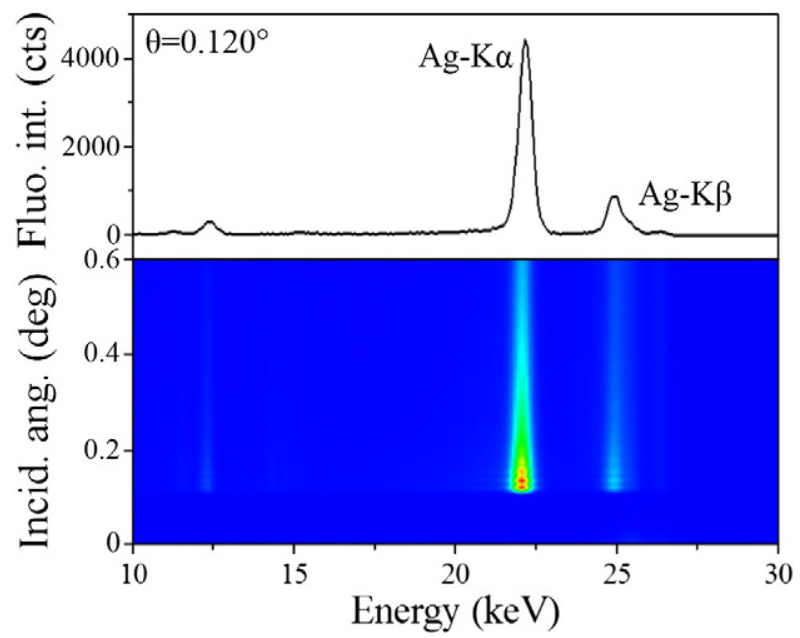

Fig. 5. Fluorescence intensity from a measurement at $26,400 \mathrm{eV}$ with a synchrotron radiation at an angle of incidence $\theta=0.12^{\circ}$. With this excitation energy, the fluorescence peaks of interest are not overlapping.

been carried out on a self-developed system with a $2 \mathrm{~kW}$ fine focus $\mathrm{Cu}$ anode tube and a multilayer monochromator selecting the $\mathrm{Cu}-\mathrm{K} \alpha$ line ( $8050 \mathrm{eV}$ ), both mounted on a theta-2theta goniometer under vacuum [13]. An Amptek Silicon Drift Detector (SDD) was used to measure the reflected beam. A Zr filter was inserted in front of this detector at low angles to reduce the primary beam intensity. The fluorescence signal was measured with a Vortex SDD placed at $\Psi_{\mathrm{d}}=90^{\circ}$ above the sample. Spectra were acquired from $\theta=0^{\circ}$ to $3^{\circ}$ with an angular step of $0.05^{\circ}$ for a total count time of approximately $1 \mathrm{~h}$.

As shown in Fig. 4, In-L and Ag-L fluorescence lines as well as Si pile-up peak overlap in the $3 \mathrm{keV}$ range. At low incidence angles (typically $<0.4^{\circ}$ ), due to the absorption of the incident beam in the top IO layer, the fluorescence signal of the Ag-L $\alpha$ line is low and completely covered by the In-L fluorescence lines. At this excitation energy, working under vacuum is necessary in order to get rid of $\mathrm{Ar}-\mathrm{K} \alpha$ lines $(2957 \mathrm{eV})$ and avoid further overlaps with the fluorescence lines of interest.

In order to overcome signal extraction difficulties due to overlaps and analyze more intense fluorescence K-lines, additional GIXRF measurements have been carried out on the Gilda (BM08) line at ESRFGrenoble. To improve the sensitivity, the measurements have been realized at $26,400 \mathrm{eV}$ above the $\mathrm{Ag}-\mathrm{K}$ but below the In-K edge. To avoid sample edge effects during the measurements, the horizontal size of the primary beam was reduced by a $50 \mu \mathrm{m}$ slit. A 13 -element

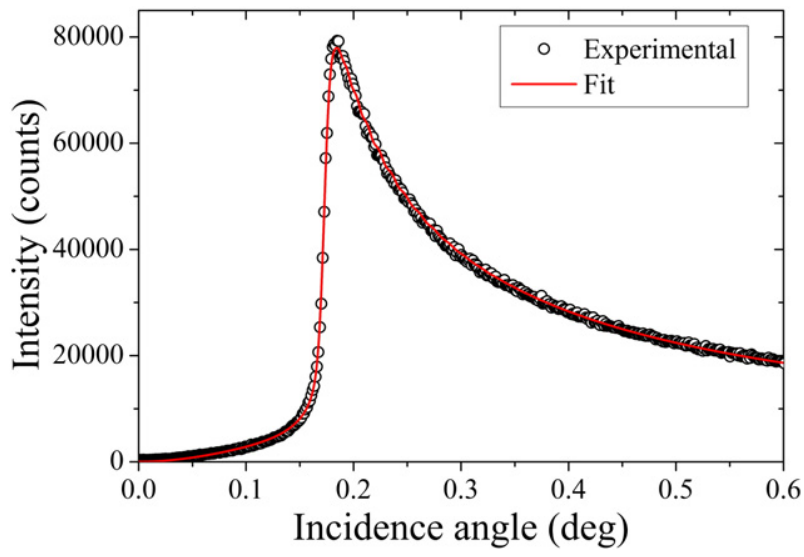

Fig. 6. GIXRF fit on JGIXA of a $50 \mathrm{~nm}$ Ni sample measured at 26,400 eV at ESRF. Fitting of reference sample allows the determination of geometrical factors such as the divergence of the beam and the size of the illuminated area.

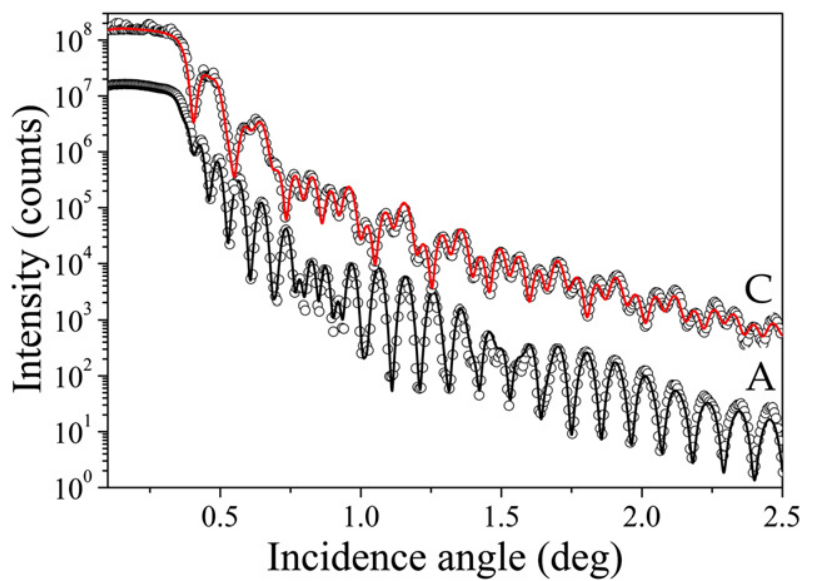

Fig. 7. XRR measurements (open circles) and fits (solid lines) of the as-deposited samples $\mathrm{A}$ and $\mathrm{C}$ at $8.05 \mathrm{keV}$.

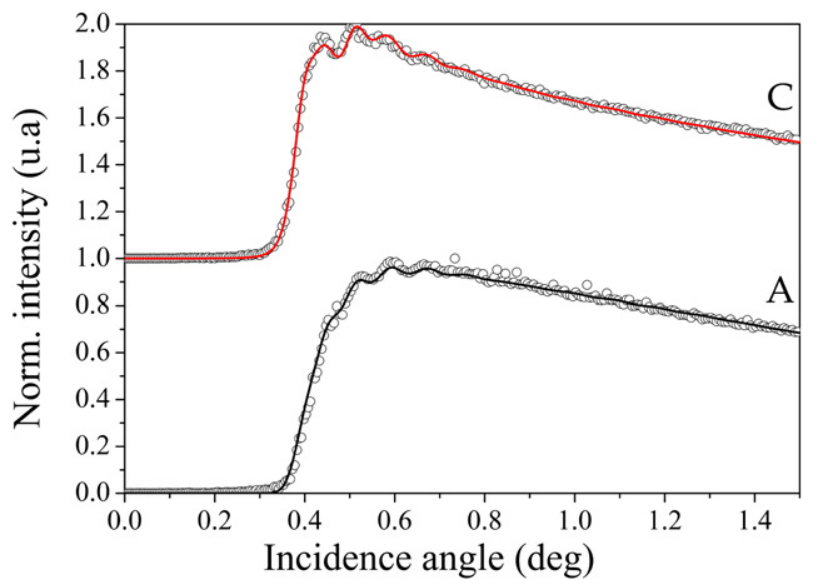

Fig. 8. Ag-L $\alpha$ GIXRF measurements (open circles) and fits (solid lines) of the as-deposited samples $\mathrm{A}$ and $\mathrm{C}$ at $8.05 \mathrm{keV}$.

high-purity Ge-SSD (solid state detector) with a maximum count rate of $80 \mathrm{k}$ counts per second was used to measure the fluorescence. Energy dispersive X-ray spectra were acquired from $\theta=0^{\circ}$ to $0.6^{\circ}$ with an angular step of $0.001^{\circ}$ for a total acquisition time of 10 minutes. The energy tunability of the synchrotron source allowed the study of the in-depth $\mathrm{Ag}-\mathrm{K} \alpha$ line isolated from the indium contributions (Fig. 5).

\subsection{Data reduction and numerical models}

Extraction of fluorescence intensities from data measured with the Cu-tube has been done using the software PyMCA [14]. The background

Table 2

Model 1-Thickness and densities of the as-deposited samples obtained by comparison of JGIXA fitting and experimental results measured with $\mathrm{Cu}-\mathrm{K} \alpha$ energy.

\begin{tabular}{lcl}
\hline Sample A & Thickness $(\mathrm{nm})$ & Density $\left(\mathrm{g} \cdot \mathrm{cm}^{-3}\right)$ \\
\hline $\mathrm{LD}-\mathrm{In}_{2} \mathrm{O}_{3}$ & $1.2 \mathrm{~nm}$ & 4.04 \\
$\mathrm{In}_{2} \mathrm{O}_{3}$ & $40.1 \mathrm{~nm}$ & 6.91 \\
$\mathrm{Ag}$ & $6.0 \mathrm{~nm}$ & 9.83 \\
$\mathrm{In}_{2} \mathrm{O}_{3}$ & $40.0 \mathrm{~nm}$ & 6.95 \\
$\mathrm{Sample} \mathrm{C}$ & Thickness $(\mathrm{nm})$ & Density $\left(\mathrm{g} \cdot \mathrm{cm}^{-3}\right)$ \\
\hline $\mathrm{LD}^{-\mathrm{In}_{2} \mathrm{O}_{3}}$ & $1.4 \mathrm{~nm}$ & 4.1 \\
$\mathrm{In}_{2} \mathrm{O}_{3}$ & $15.0 \mathrm{~nm}$ & 6.61 \\
$\mathrm{Ag}$ & $6.0 \mathrm{~nm}$ & 9.87 \\
$\mathrm{In}_{2} \mathrm{O}_{3}$ & $40.0 \mathrm{~nm}$ & 6.88 \\
\hline
\end{tabular}




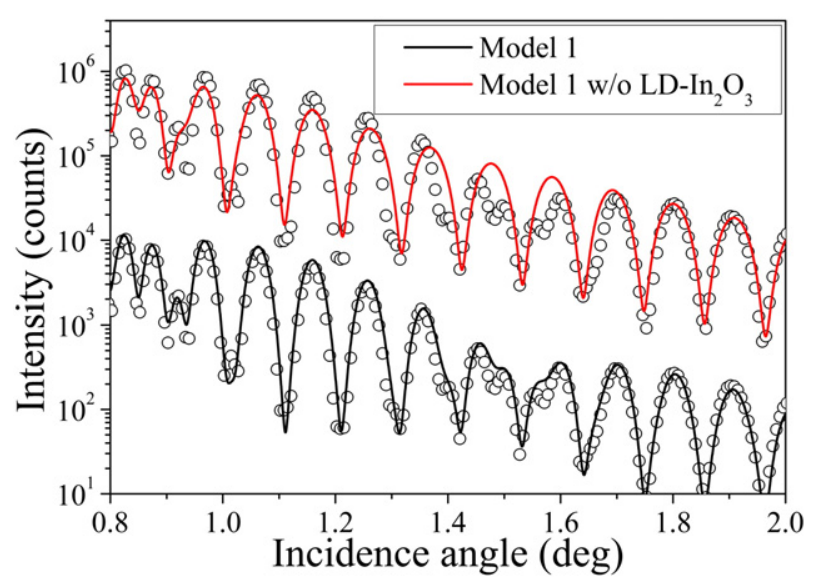

Fig. 9. XRR measurements (open circles) and fits (solid lines) of the as-deposited samples A at $8.05 \mathrm{keV}$ with and without the introduction of the low-density $\mathrm{In}_{2} \mathrm{O}_{3}$ top layer in the model. It can easily be seen that in order to reproduce the experimental data around $1.5^{\circ}$, the introduction of a low-density top layer is necessary.

has been simulated by the strip background model implemented in the software. For the measurements done at ESRF, as the peaks are not overlapped and the signal-to-noise ratio is high, the integral of the fluorescence counts in a region of interest (ROI) has been used.

The modeling of reflectivity and fluorescence measurements has been carried out using the JGIXA software [15] with two refinement configurations. As GIXRF have been acquired at different excitation energies, a first model consists in fitting XRR and GIXRF spectra acquired at the same excitation energy, while in the second model, the excitation energies of XRR and GIXRF are different.

For the optimization procedure, two sets of parameters, i.e. for the sample and the experimental setup, are defined as starting values. The sample parameters to be evaluated for each layer of the stack are the composition, thickness, mass density, and roughness. Each can be independently refined. Due to existing local minima, global optimization algorithms are required to find the global minimum. These algorithms reduce the dependency on initial values of the parameters and hence are less relying on a priori knowledge. The fitting of the measured data has been optimized with a differential evolution (DE) algorithm included in the software [16].

The angular profile of GIXRF also depends on experimental setup parameters such as the divergence of the beam, the size of the beam, and

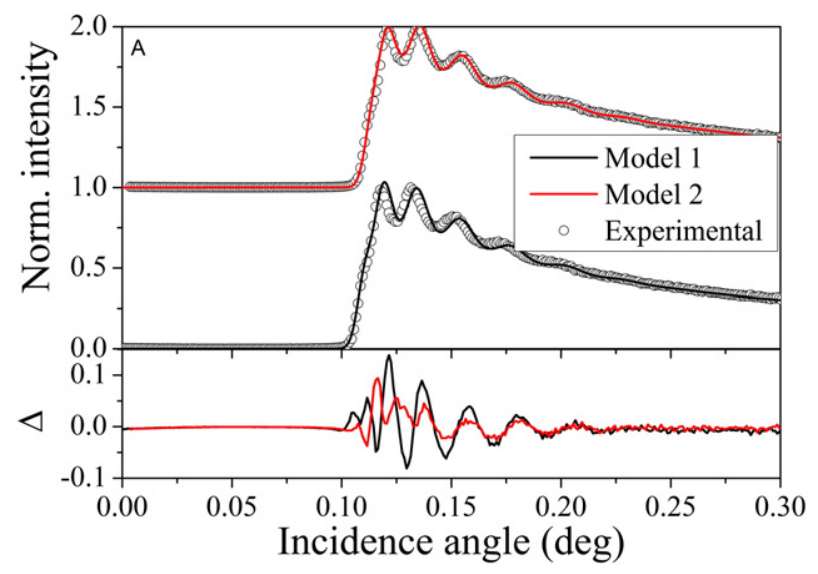

Fig. 10. Ag-K $\alpha$ GIXRF Gilda measurements and fits of sample A. The difference curve is represented at the bottom of the figure. Model 2 has been obtained by combining sets of data acquired at different excitation energies. It offers smaller differences between experimental and simulated data.

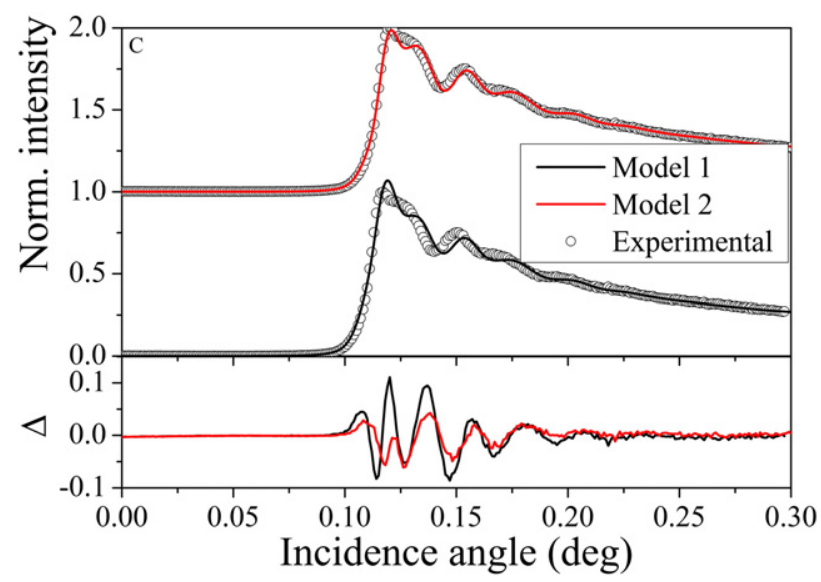

Fig. 11. Ag-K $\alpha$ GIXRF Gilda measurements and fits of sample $\mathrm{C}$. The difference curve is represented at the bottom of the figure. Model 2 has been obtained by combining sets of data acquired at different excitation energies. It offers smaller differences between experimental and simulated data.

the inspected area. They have been determined by the measurement on the same experimental setups and evaluation of already known samples. As seen of Fig. 6, a $50 \mathrm{~nm}$ Ni layer deposited on a $300 \mathrm{~nm} \mathrm{SiO}_{2} / \mathrm{Si}$ substrate has been used as reference sample for the determination of the geometrical factors. These experimental parameters are then fixed during the simulations of the TCO/metal/TCO samples.

\section{Results and discussion}

\subsection{As-deposited samples}

Data measured with the standard laboratory Cu-tube (open circles) and JGIXA simulations (solid lines) for the as-deposited samples (sample A and sample C) are shown in Figs. 7 and 8. The agreement between the experimental and simulated points is very good.

A first structure (model 1, Table 2 ) resulting from refinement of these data has been obtained. The incorporation of a top indium oxide layer with a low density (LD- $\mathrm{In}_{2} \mathrm{O}_{3}$ ) is necessary in order to reproduce all the fine details of the reflectivity curves and improve the refinement agreement (Fig. 9). For both samples, the surface and interfacial roughness ranges from 5 to $12 \AA$. The accuracy of XRR for the determination of thickness and roughness is high with uncertainties lower than $5 \AA$ and $1 \AA$, respectively [17]. Thanks to the decoupling of the sample parameters, the determination of the electronic density is reinforced by the use of the XRR and GIXRF curves for a joint fit. This aspect remains sensitive despite weak signal-to-noise ratio and rather smoothed fluorescence fringes.

Compared to the laboratory GIXRF measurements, higher-energy experiments carried out at the Gilda ESRF beam line have both the advantage of non-overlapped fluorescence lines and a much stronger

Table 3

Model 2-Thickness and densities of the as-deposited samples obtained from correlating JGIXA fits of the experimental data measured at two different energies (respectively 26.4 and $8.05 \mathrm{keV}$ )

\begin{tabular}{lcc}
\hline Sample A & Thickness $(\mathrm{nm})$ & Density $\left(\mathrm{g} \cdot \mathrm{cm}^{-3}\right)$ \\
\hline $\mathrm{LD}-\mathrm{In}_{2} \mathrm{O}_{3}$ & 0.9 & 4.44 \\
$\mathrm{In}_{2} \mathrm{O}_{3}$ & 40.1 & 7.28 \\
$\mathrm{Ag}$ & 6 & 9.8 \\
$\mathrm{In}_{2} \mathrm{O}_{3}$ & 40 & 7.1 \\
Sample C & Thickness $(\mathrm{nm})$ & Density $\left(\mathrm{g} \cdot \mathrm{cm}^{-3}\right)$ \\
\hline $\mathrm{LD}^{-\mathrm{In}_{2} \mathrm{O}_{3}}$ & 1.4 & 4.31 \\
$\mathrm{In}_{2} \mathrm{O}_{3}$ & 15 & 6.95 \\
$\mathrm{Ag}$ & 6 & 10.4 \\
$\mathrm{In}_{2} \mathrm{O}_{3}$ & 40 & 6.99 \\
\hline
\end{tabular}




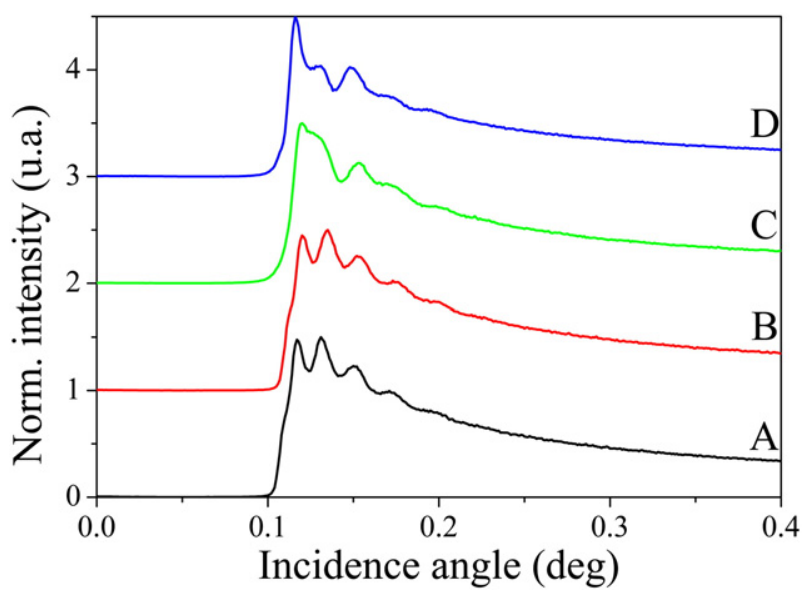

Fig. 12. Ag-K $\alpha$ GIXRF measurement of the IO/Ag/IO samples at $26,400 \mathrm{eV}$. Thinning of the top IO layer has greatly improved the sensitivity of the GIXRF technique. Differences in the GIXRF profile can be noted between the $\mathrm{C}$ (as deposited) and the D (annealed) sample.

dependence of the fluorescence intensities with the incidence angle. New simulations have been done with this set of data (Figs. 10 and 11).

By refinement of parameters, an improved model (model 2, Table 3 ) has been obtained by combining the reflectivity measured at $\mathrm{Cu}-\mathrm{K} \alpha$ energy and the fluorescence measured at the excitation energy of $26,400 \mathrm{eV}$. The difference curve between calculated and experimental data for the two models compares favorably for model 2, both for XRR and GIXRF experiments via the correction of the densities values. These density variations (around 5\% for each layer) do not have any effects on the reflectivity calculations.

The sensitivity of the combined analysis has been greatly improved by using X-ray measurement done at adapted primary energies. The joint fit of standard laboratory XRR and synchrotron-based GIXRF has provided more accurate information about the in-depth profile.

\subsection{Annealed samples}

After annealing at $200{ }^{\circ} \mathrm{C}$, we tested the efficiency of the combined XRR and GIXRF approach to detect temperature-induced modifications of the stack. In Figs. 12 and 13, the Ag-K $\alpha$ fluorescence angular intensities for the four samples are presented. Thinning of the top IO layer has improved the sensitivity of GIXRF to interfaces and reveals differences much more illustrated between samples $C$ and $D$, than between $A$ and $B$ on which only a slight shift of the whole spectra is being visible.

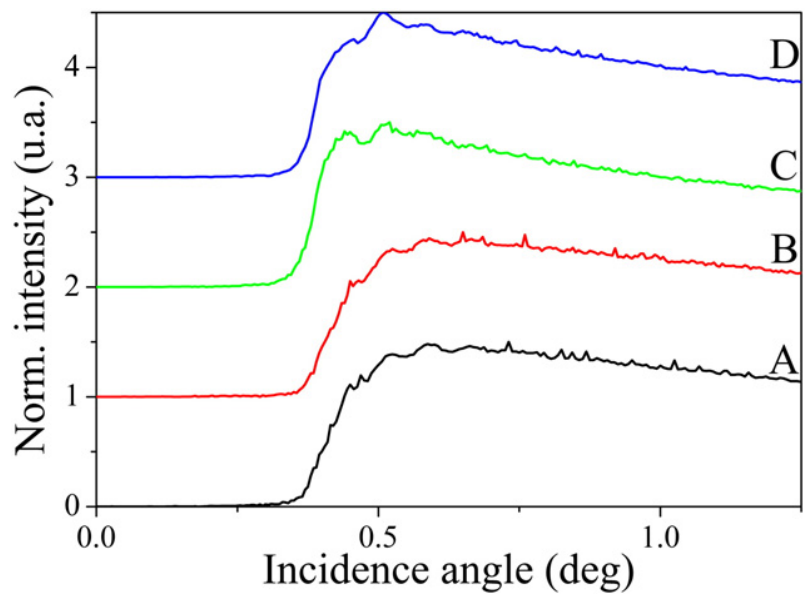

Fig. 13. Ag-L $\alpha$ GIXRF measurements of the $\mathrm{IO} / \mathrm{Ag} / \mathrm{IO}$ samples at $8050 \mathrm{eV}$. Thinning of the top IO layer has greatly improved the sensitivity of the GIXRF technique. Differences in the GIXRF profile can be noted between the $\mathrm{C}$ (as deposited) and the $\mathrm{D}$ (annealed) sample.
Table 4

Thickness and densities of the sample D obtained from correlating JGIXA fits of the experimental data measured at two different energies (respectively 26.4 and $8.05 \mathrm{keV}$ ).

\begin{tabular}{lcl}
\hline Sample D & Thickness $(\mathrm{nm})$ & Density $\left(\mathrm{g} . \mathrm{cm}^{-3}\right)$ \\
\hline $\mathrm{LD}-\mathrm{In}_{2} \mathrm{O}_{3}$ & 2 & 6.12 \\
$\mathrm{In}_{2} \mathrm{O}_{3}$ & 16.3 & 7.18 \\
$\mathrm{In}_{2} \mathrm{O}_{3} ; \mathrm{Ag}$ & 1.1 & 8.36 \\
$\mathrm{Ag}$ & 5.7 & 9.9 \\
$\mathrm{In}_{2} \mathrm{O}_{3} ; \mathrm{Ag}$ & 0.6 & 7.47 \\
$\mathrm{In}_{2} \mathrm{O}_{3}$ & 40 & 7 \\
\hline
\end{tabular}

Such behavior was also observed on the Ag-L $\alpha$ GIXRF profiles measured with laboratory instrument.

One could interpret this difference in the GIXRF profile as an annealed-induced interdiffusion between the $\mathrm{Ag}$ and the $\mathrm{In}_{2} \mathrm{O}_{3}$ layers. We tested a rough model for such an interdiffusion by incorporating intermediate density $1 \mathrm{~nm}$ thick layers around the $\mathrm{Ag} / \mathrm{In}_{2} \mathrm{O}_{3}$ interfaces (Table 4). The results of the combined fit of the lab-based XRR and synchrotron-based GIXRF are presented in the Fig. 14 and Table 3. The simulation highlights the diffusion of the $\mathrm{Ag}$ as an intermixing of elements is obtained in the transition layers. The surface and interfacial roughness ranges from 4 to $10 \AA$.

The combination of XRR and GIXRF allows detecting and characterizing a thin diffusion profile at the interface of two layers. Even on non-optimized experimental setup (i.e. laboratory Cu-tube), the diffusion induced by thermal annealing is noticeable.

\section{Conclusions and outlook}

The combined evaluation of GIXRF and XRR resulted in a nondestructive and precise characterization of the $\mathrm{In}_{2} \mathrm{O}_{3} / \mathrm{Ag} / \mathrm{In}_{2} \mathrm{O}_{3}$ multilayered structure. It has been shown that the sensitivity of the joint approach can be optimized with the choice of the primary energy.

A thin interdiffusion profile induced by annealing has been observed and characterized. Sensitivity to structural changes in the depth of $0.5-$ $1 \mathrm{~nm}$ was achieved for measurements performed at a synchrotron facility but also for the ones acquired with the laboratory experimental setup.

The effect of the annealing on material properties such as the crystallographic phase, the size of the crystallites, and the residual stress have been observed by X-ray diffraction measurements (XRD). In order to obtain a full characterization of these photovoltaic devices, the combination of XRD, XRR, and GIXRF in respect with the models presented in this work will be done.

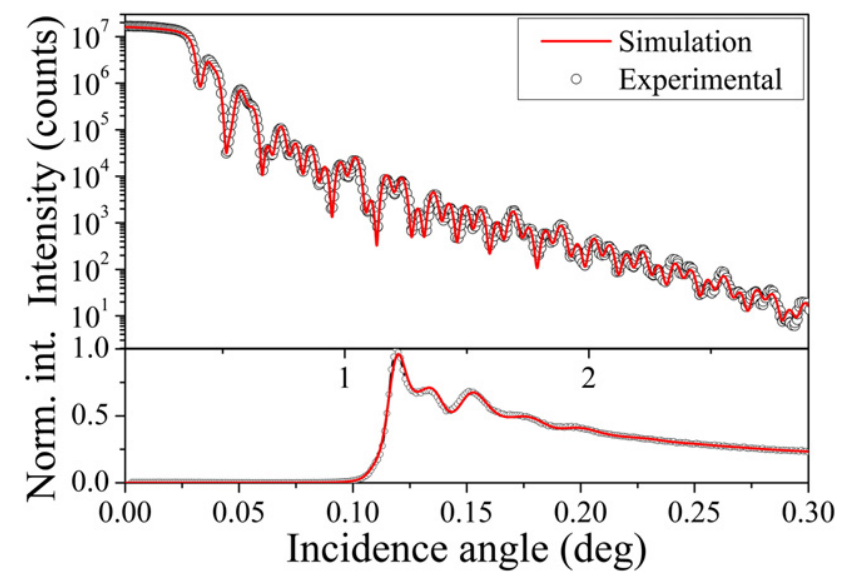

Fig. 14. XRR and GIXRF measurements and fitting of the sample D with reflectivity measured at $8.05 \mathrm{keV}$ and fluorescence at $26.4 \mathrm{keV}$. 


\section{References}

[1] H. Hosono, Recent progress in transparent oxide semiconductors: materials and device application, Thin Solid Films 515 (2007) 6000-6014.

[2] C.G. Granqvist, Transparent conductors as solar energy materials: a panoramic review, Sol. Energy Mater. Sol. Cells 91 (2007) 1529-1598.

[3] M. Fahland, T. Vogt, W. Schoenberger, N. Schiller, Optical properties of metal based transparent electrodes on polymer films, Thin Solid Films 516 (2008) 5777-5780.

[4] D.R. Sahu, S.-Y. Lin, J.-L. Huang, $\mathrm{ZnO} / \mathrm{Ag} / \mathrm{ZnO}$ multilayer films for the application of a very low resistance transparent electrode, Appl. Surf. Sci. 252 (2006) 7509-7514.

[5] Low resistance and highly transparent ITO-Ag-ITO multilayer electrode using surface plasmon resonance of Ag layer for bulk-heterojunction organic solar cells, Sol. Energy Mater. Sol. Cells (2009) 1801-1809.

[6] C. Guillén, J. Herrero, TCO/metal/TCO structures for energy and flexible electronics, Thin Solid Films 520 (2011) 1-17.

[7] M. Müller, P. Hönicke, B. Detlefs, C. Fleischmann, Characterization of high-k nanolayers by grazing incidence X-ray spectrometry, Materials 7 (2014) 3147-3159.

[8] A. Lesnik, J. Bläsing, J. Hennig, A. Dadgar, A. Krost, Characterization of AlInN/AlN/GaN FET structures using X-ray diffraction, $\mathrm{X}$-ray reflectometry and grazing incidence X-ray fluorescence analysis, J. Phys. Appl. Phys. 47 (2014) 355106.

[9] D.K.G. de Boer, Glancing-incidence X-ray fluorescence of layered materials, Phys. Rev. B Condens. Matter 44 (1991) 498-511.

[10] J. Daillant, A. Gibaud (Eds.), X-ray and Neutron Reflectivity, Springer Berlin Heidelberg, Berlin, Heidelberg, 2009.
[11] D. Ingerle, M. Schiebl, C. Streli, P. Wobrauschek, Combination of grazing incidence X-ray fluorescence with x-ray reflectivity in one table-top spectrometer for improved characterization of thin layer and implants on/in silicon wafers, Rev. Sci. Instrum. 85 (2014) 083110.

[12] D. Giubertoni, G. Pepponi, S. Gennaro, M. Bersani, M.A. Sahiner, S.P. Kelty, et al., Correlation of local structure and electrical activation in arsenic ultrashallow junctions in silicon, J. Appl. Phys. 104 (2008) 103716.

[13] D. Ingerle, F. Meirer, N. Zoeger, G. Pepponi, D. Giubertoni, G Steinhauser, et al, A new spectrometer for grazing incidence X-ray fluorescence for the characterization of Arsenic implants and Hf based high-k layers, Spectrochim. Acta B At. Spectrosc. 65 (2010) 429-433.

[14] V.A. Solé, E. Papillon, M. Cotte, P. Walter, J. Susini, A multiplatform code for the analysis of energy-dispersive X-ray fluorescence spectra, Spectrochim. Acta 62 (2007) 63-68.

[15] D. Ingerle, F. Meirer, G. Pepponi, E. Demenev, D. Giubertoni, P. Wobrauschek, et al. Combined evaluation of grazing incidence X-ray fluorescence and X-ray reflectivity data for improved profiling of ultra-shallow depth distributions, Spectrochim. Acta B At. Spectrosc. 99 (2014) 121-128.

[16] R. Storn, K. Price, Differential evolution - a simple and efficient heuristic for global optimization over continuous spaces, J. Glob. Optim. 341-359 (1997).

[17] K.N. Stoev, K. Sakurai, Review on grazing incidence X-ray spectrometry and reflectometry, Spectrochim. Acta B At. Spectrosc. 54 (1999) 41-82. 